that the successful prosecution of such investigations by the smaller Local Societies would be greatly encouraged and facilitated by the general interest shown in their work by the more influential societies in their neighbourhood, by a watchful oversight, a readiness to discuss and publish results, and by the personal influence of their leading members. The Committee offer tre recommendations they are about to make in the tru: $t$ that, if the Council are pleased to publish them, they will serve to remind the more important Local Societies of the high and useful function they are able to perform by entering into friendly and helpful relations with the small and scattered societies of their respective-districts, and by offering themselves as their scientific representatives wherever representation may be necessary.

The Committee recommend that they be empowered to print and circulate among the Local Societies the following draft of suggested rules, to give an opportunity to those societies of taking that initiative without which no action on the part of the Association is likely to produce much effect. After the Committee have been informed of the views of these societies, they will be in a better position than they are at the present moment for appreciating at its true value the desire for cooperation which they believe to exist. They will also perhaps receive useful suggestions from the societies that have not occurred to themselves, and they will probably be in a position to submit their final recommendations before the approaching annual meeting.

"Suggested New Rules, the Existing Rules being ALTERED ACCORDINGLY.

"Corresponding Local Societies.

"Application may be made by any society publishing scientific memoirs to be placed on the list of Corresponding Local Societies of the British Association. These applications must be addressed to the Secretary, and be made on or before the second day of the annual meeting, and they must be accompanied with a copy of the publications of the Society during the preceding year.

"The Secretary shall transmit the e applications to a Committee appointed by the Council for the purpose of con-idering them, as well as for that of keeping themselves generally informed of the annual work of the Corresponding Local Societies. This Committee shall make an annual report to the Committee of Recommendations, and shall suggest such additions or changes in the list as they may think desirable; but the final determination of the list will rest with the Committee of Recommendations, subject only to the conditions-(I) That the number of Societies on the list shall not exceed that which is prescribed by the Council ; (2) that the intended removal of any Society from the list shall not take effect until immediately before the commencement of the next annual meeting.

"The privileges of a Corresponding Local Society shall consist in-(a) The insertion in the Annual Report of the British Association of an index, in such abbreviated form as the Counci may sanction, of the titles of the scientific memoirs published by the Society during the previous year; $(b)$ the right to nominate any one of its members, who is also a member of the British Association, as its delegate to the annual meeting of the Association, who shall have for the time the rights of a member of the General Committee.

"Before the delegate can enter into his rights, he must trans. mit to the Secretary of the British Association a copy of the publications during the previous year of the Society he represents. He must also fill up a schedule, that will be furnished to him by the Secretary on application. This schedule wi'l ask for- $-(a)$ The names of the President and chief executive officer of his Society; $(b)$ a list of the institutions, if any, in its neighbourhood with which it bas official relations and whose interests it represents ; $(c)$ a brief report on the character, number, and results of any systematic local observations carried on during the past year, either by itself or by any of the institutions on the foregoing list: (I) at the instance of Committees of the British Association, (2) at the instance of other Societies or private persons; $(d)$ such other information as may be thought desirable.

"The delegates of the various Corresponding Local Societies shall constitute a Committee, which shall be summoned by the Secretary of the Association to hold one or more meetings during each annual meeting of the Association, under a Chairman and with a Secietary appointed by the Council. The Secretaries of each Section shall be instructed to transmit to the
Secretary of the Committee of Delegates copies of any recom. mendations forwarded by the Pre:idents of Sections to the Committee of Recommendations bearing upon matters in which the cooperation of Local Societies is desired; and the Secretary to the Committee of Delegates shall invite the authors of those recommendations to attend the meefing of the Committee an $t$ give verbal explanations of their objects and of the precise way in which they would desire to have them carried into effect, and to discuss difficulties that may be raised by any member of the Committee, so that the Delegates may be qualified on their return to bring those recommendations clearly and favourably before the notice of their respective Societies."

The Committee believe that the distinction accorded to a Local Society through its selection and formal recognition by the British Association as one of its Corresponding Societies, the advantage of a widely-circulated notice of its work in so important a volume as the Report of the British Association, and the honourable and useful duties as:igned to its delegate, would give considerable value to the title.

They also anticipate that a Local Society, which had asked for and received recognition as the representative centre for the time being of the institutions in its district, would be thereby stimulated to exercise that very creditable and important function with increased zeal and efficiency. The result would be to strengthen the mutual relations of the larger and the smaller Local Societies, to insure the encouragement of any disposition to engage in systematic investigations, and to establish a practice of printing the scattered results obtained by the smaller Local Societies of any district in a consolidated form in the publications of their leading Society.

Finally, the Committee believe that the annual meetings of the proposed Committee of Delegates, under the chairmanship of a distinguished member of the Association, would have large influence in harmonising the action of their several Societies, and that it would offer a facility that does not now exist for the natural and healthy growth of a federation between remote Societies which have no more direct bond of union than througl the British A:scciation.

\section{THE ROYAL OBSERVATORY}

$T H E$ following are the leading points referred to in the Report of the Astronomer Royal to the Board of Visitors of the Royal Observatory, Greenwich, read at the annual visitation on June 2.

On the subject of Astronomical Observations Mr. Christie says :- -

"The regular subjects of observation are the sun, moon, planets, and fundamental stars, with other stars from a selected list. The working catalogue of 2500 stars down to the fifth magnitude having been cleared off, a new working list of 2600 stars, comprising all stars down to the sixth magnitude inclusive which had not been observed since 1860 , has been prepared, and was brought into use at the beginning of March. About 1200 stars were observed in $I \delta 82$, but amongst these there are nearly 5co single observations, necessitating careful comparison with catalogue place for the detection of any mistakes of observation or reduction. The labour thus entailed is considerable, and efforts will be made to obtain in this and each future year at least two observations of every star observed.

"The following statement shows the number of observations with the transit-circle made in the year ending 1883 , May 20 :Transits, the separate limbs being counted as

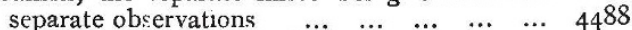

Determinations of collimation error $\quad \ldots \quad \ldots \quad \ldots \quad \ldots \quad 354$

$\begin{array}{lllllll}\text { Determinations of level error } & \ldots & \ldots & \ldots & \ldots & 323\end{array}$

$\begin{array}{llllllll}\text { Circle observations } & \ldots & \ldots & \ldots & \ldots & \ldots & \ldots & 4485\end{array}$

Determinations of nadir point (included in the

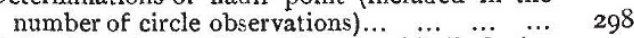

Reflection observations of stars (similarly included)

"Comet $a$ I 882 bas $\dddot{b}$ been observed seven times on the meridian since the date of the last Report, and Comet $b 1882$ has been observed three times.

"As regards the computations-

Clock times of transit over the true meridian after all corrections for instrumental errors

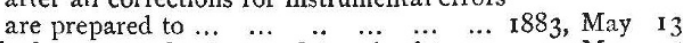

Clock errors and rates are determined to ... May 5

Mean R.A.'s on 1883 , January I, are formed

$$
\begin{array}{llllllllll}
\text { to } \ldots & \ldots & \ldots & \ldots & \ldots & \ldots & \ldots & \ldots & \ldots & \text { April } 25
\end{array}
$$


"The investigation of personal equations has been completed for the year I882, the results being very accordant with those found in the preceding year.

"The circle observations are completely reduced so as to form mean N.P.D. for 1883 , January $I$ to April 2I, apparent Z. D.'s being formed to April 28 .

"From the beginning of this year a correction of $-\mathrm{o}^{\prime \prime} \cdot 39$ has been applied to the results of the nadir observation to make them agree in the mean with the results of reflection of servations of stars. This correction has been deduced from a comparison of the nadir results throughout $\mathbf{I} 822$ with corresponding reflection results for stars north and south of the zenith. The discordance appears to be increasing, and its source has not yet been traced. It does not appear to originate on this occasion with the microscope-micrometer or telescope-micrometer, and it is not connected with the extension of the range of observation of stars by reflection. The discordance, which was insignificant in 1878 , amounting only to $-\mathrm{O}^{\prime \prime} \cdot 03$, has gradually increased since, being $-0^{\prime \prime} \cdot 10$ in $1879,-0^{\prime \prime} \cdot 29$ in $1880,-0^{\prime \prime} \cdot 30$ in $188 \mathrm{r},-0^{\prime \prime} \cdot 39$ in I882, and for the first four months of this year $-0^{\prime \prime} \cdot 58$.

"Determinations of flexure have been made on 1882, Decem. ber 30 , and 1883 , May ro and 18 , the resulting values being $-0^{\prime \prime} \cdot 07$ and $-0^{\prime \prime} \cdot 78$ and $-0^{\prime \prime} \cdot 33$. The observations on May 18 were not altogether satisfactory, as the sun was shining during the second set of measures. The values resulting from the first and second sets respectively are $-0^{\prime \prime} \cdot 72$ and $+0^{\prime \prime} \cdot 05$. There is apparently nothing in the observations on May 10 to accoun for the exceptionally large value found on that day. No correc tion for flexure, as apart from the correction for $R-D$, has been applied to the observations.

"The correction for $\mathrm{R}-\mathrm{D}$, the error of assumed colatitude, and the position of the ecliptic have teen investigated for 1882 . For the planetary results, errors of R.A. and N.P.D. have been formed, but the heliocentric errors have not yet been computed.

"The reflection observations of stars available for investigation of the $\mathrm{R}-\mathrm{D}$ discordance extend from Z.D. $71 \frac{1}{2}^{\mathrm{c}}$ north to Z.D. $70 \frac{1}{2}^{\circ}$ south, and the discussion of these shows discordances steadily increasing from the zenith towards the horizon, and amounting to $-\mathrm{I}^{\prime \prime} \cdot 5^{8}$ for the group at Z.D. $68 \frac{1}{4}^{\circ}$ north and to $+1^{\prime \prime} \cdot 66$ at Z.D. $70^{\circ}$ south, a correction of $+\mathrm{c}^{\prime \prime} \cdot 16 \sin$ Z.D. having been first applied to the reflection observatious for inclination of the vertical at the mercury trough. It is quite evident that the discordances do not follow any such law, as $a+b$ $\sin z \cdot \cos ^{2} z$, which was used from 1862 to 1880 . Assuming the law $a+b \sin z$, which was adopted in the years preceding $\mathbf{I} 862$ and in 1881 , the $R-D$ ccrrection for 1882 would be $+0^{\prime \prime} \circ$ $+u^{\prime \prime} 42 \sin z$, and for the sake of contiuuity in the system of reductions this correction has been provisionally adop'ed for use in I882. But the discordances between this formula and the observed quantities increase. regularly from the zenith towards the horizon, amounting to half of the observed quantities at Z.D. $50^{\circ}$ to $60^{\circ}$. The formula $+0^{\prime \prime} \cdot 08+0^{\prime \prime} \cdot 29 \tan z$ represents the observations better, though even this does not give sufficiently large results at large zenith distances. In this discussion colresponding reflection and direct observations made on the same day have alone been $\mathrm{u}$ ed.

"The value found for the colatitude from the observations of $\mathbf{I} 882$ is $38^{\circ} 3 \mathbf{I}^{\prime} 2 \mathbf{I}^{\prime \prime} \cdot 93$, very slightly larger than the assumed value; the correction to the tabular obliquity of the ecliptic is $+\mathrm{O}^{\prime \prime} 44$; and the discordance between the results from the summer and winter solstices is $+\alpha^{\prime \prime} 37$.

"The mean error of the moon's tabular R.A. from observations with the transit-circle in 1882 is $+0.82 \mathrm{~s}$.

"The following observations have been made $\mathrm{n}$ ith the altazimuth from I882, May 20, to 1883 , May 20 :-

Azimuths of the moon and stars $\ldots \begin{array}{llllll}\ldots & \ldots & \ldots & \ldots & 317\end{array}$

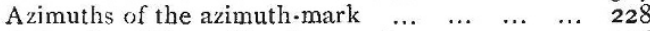

$\begin{array}{llllll}\text { Azimuths of the collimating-mark } & \ldots & \ldots & \ldots & 216\end{array}$

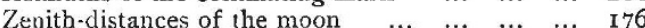

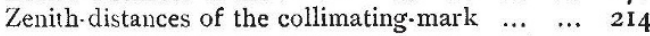

"Azimuths and zenith-distances of Comet $b$ I882 were observed on a single day.

"The altazimuth observations are completely reduced to May 6, so as to exhibit errors of moon's tabular R.A., N.P.D., longitude, and ecliptic N.P.D. The restriction of the observatio $\mathrm{s}$, and the limitation of the computations to $0^{\circ} \mathrm{OIS}$, and $\mathrm{O}^{\prime \prime} \cdot \mathrm{I}$ have made these reductions comparatively light.

"'The moon's diameter has been measured-
With the transit-circle, twice in R.A., I 7 times in N.P.D.

With the altazimuth, 4 times in azimuth, Io times in Z.D."

On the subject of Equatoreals Mr. Christie states:-“A very valuable addition has been made to the insiruments of the Royal Observatory by the gift of the Lassell two-feet reflecting equatoreal, which has been generously presented by the Misses Lassell. The exceptional qualities of this fine telescope (with which Hyperion was discovered in 1848 ) are well known, and there could be no he:itation in accepting on the part of the Admiralty the offer of such a valuable gift. The instrument was removed from Maidenhead early in March, and has been erected in the south ground, where it commands a nearly unobstructed view of the sky to within about $5^{\circ}$ of the horizon. A circular building 30 feet in diameter, has been erected for the Lassell telescope, and the construction of a suitable dome is authorised. There are two large mirrors available for use, and $I$ contemplate taking advantage of the firm mounting and perfect clock movement of the south-east equatoreal to mount the spare mirror on this instrument, attaching it to the tube of the refractor, so as to have on the same mounting a refractor and reflector with their axes parallel. The former would be available for eye observation, whilst the latter could be used on the same object for physical work, spectroscopic or photographic. The Lassell telescope itself would be well suited for observation of faint satellites and comets which are beyond our present instrumental $m+$ ans.

"The observations of the solar eclipse of 1882, May 17, with the south-east equatoreal are completely reduced, and the final equations have been solved.

"The spectroscopic observations during the past twelve months have been somewhat restricted through the pressure of the photographic reductions at a time of maximum of sunspot frequency. The solar prominences have been observed with the half-prism spectroscope on eight days, and four sunspots have been examined on eight days with reference to the broadening of lines in their spectra. The sfectrum of the great spot of 1882, Noveniber 12-25, showed some remarkabie reversals of the lines of hydrogen and sodium, and an extraordinary displacement of the $F$ line.

"As regards the determination of motions of stars in the line of sight, 142 measures have been made of the displacement of the $\mathrm{F}$ line in the s ectra of 23 stars, and 26 measures of the $b_{1}$ line in 9 stars. The observations of Sirius during the past winter tend on the whole to confirm the impression that the rate of recession of this star has diminished progressively since 1877 , and that the motion is now on the point of being converted into one of approach.

"The spectrum of Comet $a$ I 882 was examined on three nights, that of the great Comet $b \mathbf{I} 882$ on three nights, and that of Comet $a \quad 1883$ on one night. The spectrum of the firstnamed object showed the yellow sodium lines with great brilliancy just before perihelion passage. The spectrum of the aurora of 1882 , November I 7 , и as also examined.

"The spectroscopic observations of all kinds have been completely reduced to $\mathrm{I}_{8} 8_{3}$, May 20 .

"In the year ending I 883 , May 20, photographs of the sun have been taken on 200 days, and of these 339 have been selected for preservation. There were 7 days on which the sun's disk was observed to be free from spots. The number and size of spots and faculæ continued to increase in a marked way till last November, when a group of spots of very unusual size appeared. Since that date, however, the sun has become more quiescent.

"Since the beginning of December, gelatine dry plates have been used instead of the old wet-plate process. They are more convenient in use, and appear to give as good average results. The photographs on a scale of 8 inches to the sun's diameter recently obtained in India, under the auspices of the Solar Physics Committee, are so successful that the Committee have recommended the general adoption of this rcale, and I propose, as soon as we have a spare photoheliograph returned from the Eclipse Expedition, to have it altered in the same manner as the Indian photoheliograph, so as to obtain eight-inch photographs of the sun instead of four-inch.

"It was suggested in the last Report that the measurement of such of the Indian and other photographs as nere required to fill up gaps in the Greenwich series might with advantage be undertaken here. This proposal has now been carried out, and I I photographs for the period from 188I, December 22, to I882, October I9, have been received from the Solar Physics 
Committee, so that a record of the condition of the sun on 279 out of the 302 days in that interval is now presented. From 1882 October 20 , eight-inch photographs were taken in India, and fur the measurement of these a special micrometer has been ordered of Messrs. Troughton and Simms by the Solar Physics Commitree.

"All the ph.stographs received from the Solar Physics Committee have been measured in duplicate, and the mea iures have been co npletely reduced so as to exhibit heliographic longitudes and latitudes of spots, and areas of spots and faculæ, from I 88I, December 22, to I882, October I9, the end of the series of fourinch p'rotograph:

"Magnetical Observations :-

"The course of observation continues the same a: in former years, changes in the magnetic declination, horizontal force, and vertıcal force being continuously recorded by photography with the three magnetometers, whilst absolute values of mignetic declination, dip, and hurizontal force are found by eye observation. Earth-currents in two directions nearly at right angles to each sther are als , photographically registered.

"A great impruve nent has been made in the photographic registrition by the substitution in June last of Mrgan and Kidd's arsentic-gelatino-biomide paper with ferrous oxalate development for the old photographic process.

"The large temperature correction of the vertical force magnet has been reduced to less than one-fourth of its forme amount by some alterations which were carried out by $\mathbf{1 1 r}$. Simms last autumn. The effect of these alterations has been to reduce the correction for change of $\mathrm{I}^{\circ}$ Fabrenheit from 0.00088 of the vertical force to about 0.00020 . The cuefficient, ha:, however, still the opposite si n to that which would result from mere loss of magnetic power with increase of temperature. It is intended to make an attempt to still further diminish the temperature correction by shifting the magnet in its carrier so as to reduce the horizontal sta!k and balance weight.

"It was remarked in the last Report that the earth-current registers frequently showed abnormal di-turhance during rain. By the kindue s of Mr. Le onard (the succe sor to the late $\mathrm{Mr}$. C. V. Walker, as telegraph engineer of the South-Eastern Rail way), the wires were repaired in February, and the rain disturbance seems now to have disappeared.

"The following are the principal results for magnetic elements for 1882 :-

$$
\begin{aligned}
& \text { Approximate mean westerly } \\
& \begin{array}{llllll}
\text { declination } & \ldots & \ldots & \ldots & \mathbf{1} 8^{\circ} & \mathbf{2 2} \\
\end{array}
\end{aligned}
$$

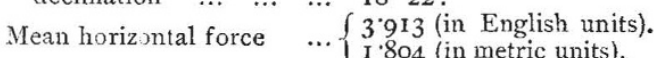

$$
\begin{aligned}
& \text { Mean dip } \quad \ldots \quad \ldots \quad \ldots\left\{\begin{array}{llll}
6 & 1 & 11 & \\
67 & 33 & 33 & \text { (by } 9 \text {-inch needles). } \\
67 & 34 & 34 & \text { (by } 6 \text {-inch needles). }
\end{array}\right. \\
& \left\{\begin{array}{lll}
67 & 34 & 14
\end{array} \text { (by } 3\right. \text {-inch needles). }
\end{aligned}
$$

"There has been considerable magnetic activity during the year, the month of November, which was characterised by the appearance of a very large sunspot, being particularly disturbed with remarkable magnetic storms on November 17,19 , and 20, and many interesting cases of lesser disturbance. The magnetical changes in November are so intere ting in relation to the accompanying outburst of sunspots that it seems desirable to have the registers for a great part of the month as well as for other days of magnetic disturbance in the year lithographed in the 'Greenwich Magnetical Results for $\mathbf{I} 882$ ' on a reduced scale. The character of a disturbance would, I think, be much better shown by a reproduction of the curves traced on thf photographic sheets than by tables of numerical values oe ordinates. I am making inquiries as to the practicability of using some anastatic process, which would not be very expensive.

"The magnetic disturbances on October 2 and November I7 were accompanied by brilliant auroras.

"Particulars of magnetic disturbances are regularly communicated to the Colliery Guardian newspaper for the information of mining surveyors.

"Meteorological Observations :-

"On the occasion of the gale of 1882, October 24, a velocity of 64 miles an bour was registercd with Robinson's anemometer for tuo successive hours, being greater than any velocity previously recorded here, but the greatest pressure registered $\mathrm{w}$ ith the chain was only $29 \mathrm{lbs}$ on the square foot, whilst on I882, A pril 29, a pressure of $49 \frac{1}{2}$ lbs. was recorded with the copper wire at a time when the velocity was only 50 miles an hour.
" The observations of temperature of the Thames have recently been resumed under the charge of the Corporation of London, who have instructed Mr. G. J. Symons to arrange details. The observation: are now made at the e:t of one of the jetties of the Foreign Cattle Market at Deptford, where a record is to be kept (by means of two Six's thermometers) of the daily maximum and minimum temperatures of the Thames at a depth of 2 feet below the surface, and also near the bottom of the river. Mr. Symons has arranged that these observations shall be regularly communicated to the Royal Observatory to be included in the meteoroloyical tab e published weekly in the Re ristrar-General's Report:

"The mean temperature of the year 1882 was $49^{\circ} \%$, being $0^{\circ}$. I lower than the average. The highe $t$ air temperature was $81^{\circ} \cdot 0$ on August 6 , and the lowest $22^{\circ} \cdot 2$ on December II. The mean monthly temperature was above the average from January to May, then below until Septemher. In October, November, and December it differed little from the average.

"The mean daily motion of the air in 1882 was 306 miles, being 27 miles greater than the average. For the month of November the mean daily motion was 449 miles, being 159 miles above the average. The greatest daily motion was $75^{8}$ miles on November 4, and the lea t 30 miles on December I I. As already mentioned, the greatest hourly velocity was 64 miles an hour, and the greatest pressure (with the chain) 29 lbs. on October 24 .

"During the year I882 Osler's anemometer showed an excess of II revolutions of the vane in the positive direction N., E., S., W., N., if all th $*$ turnings are counted (as has been the practice in former years); or of 23 revolutions in the positive direction if the turning; wbich are evidently accidental are excluded.

"The number of hours of bright sunshine recorded by Campbell's sunshine instrument during I 882 was I 245 , which is more than $40 \mathrm{~h}$ urs above the average of the 5 preceding years.

"The rainfall in 1882 war $25^{\circ} 2$ inches, being very slightly above the average.

"The Westminster clock has maintained its high character, its errors having been under Is. on 66 per cent. of the days of observation, between Is. and 2s. on 25 per cent., between 2 s. and 3 s. on 6 per cent., and between 3 s. and 4 s. on 3 per cent. The error has never exceeded $4 \mathrm{~s}$.

Mr. Christie concludes as follow's :--

"The changes suggested in the lait Report bave been carried out, and will, I trust, tend to increase the efficiency of the Observatory. The restriction of the altazimuth observations of the moon to the semi-lanation from last quarter to first quarter has enabled $u$ : to devote more attention to equatoreal observations, though the results hitherto obtained have been somewhat limited through the inadequacy of our instrumental means. The presentation of the Lassell telescope has now removed this difficulty, and when this fine instrument is in working order we may hope to be able to take up with success observations of comets, faint satellites, and other objects of interest. In regard to the spectroscopic observations we have now two observers available, and it may be expected that in the coming year we shall reap the full benefit of the arrangement by which Mr. Nash takes a share in this work.

"In solar photography we have undertaken the measurement and reduction of Indian photograpbs, supplementing those taken at Greenwich from the commencement of 1882 . The Solar Physics Committee propose to undertake the arrears of this work for preceding years.

"In some slight degree the past year has been one of transition and of preparation for future work. Some administrative changes have been made, and the observers have been gaining experience in some new directions; but the regular course of observation and reduction has not been disturbed, and it has been my special endeavour to maintain the standard meridian observations in full vigour-a task in which I have received the hearty cooperation of all the staff.

"In regard to the coming year, I may mention one special work of meteorological reductions which it seems desirable t.) take in hand. The hourly ordinates of barometer and thermometer registers have been read out and tables of mean values formed for the 20 years of the meteorological reductions, and also year by year since 1877 ; but there is a gap of three years for the barometer (1874-1876), and of 8 years for the thermometer (1869-1876), for which the photographs have not been discussed. The continuity of the Greenwich series is thus broken, and the results are not available to their full extent. The dis- 
cussion which I contemplate for the years in question would probably occupy one computer for a year and a half, involving an outlay of about $7 \mathrm{ol.}$.

\section{ON THE DARK PLANE WHICH IS FORMED} OVER A HEATED WIRE IN DUSTY AIR ${ }^{1}$

I $\mathrm{N}$ the course of his examination of atmospheric dust as rendered evident by a conversent beam from the electric arc, Prof. Tyndall noticed the formation of streams of dust-free air rising from the summits of moderately heated solid bodies (Proc. Roy. Inst., vul. vi. p. 3, 1870). "To study this eftect a platinum wire was stretcted across the beam, the two ends of the wire being connected with the two poles of a galvanic battery. To regulate the strength of the current a rheostat was placed in the circuit. Beginning with a feeble current, the temperature of the wire was gradu:lly augmented ; but before it reached the heat of ignition, a flat stream of air rose from it, which, when l oked at edgeways, appeared darker and sharper than one of the blackest lines of Fraunhofer in the solar spectrum, Right and left of this dark vertical band the floating matter rose upwards, bounding definitely the non-luminous stream of air." . . .

"When the fire is white hot it sends up a band of intense darkness. This, I say, is due to the destruction of the floating matter. But even when its temperature does not exceed that of boiling water, the wire produces a dark ascending current. This, I say, is due to the distribution of the floating matter. Imagine the wire clasped by the mote-filled air. My idea is that it heats the air and lightens it, withont in the same degree lightening the floating matter. The tendency, therefore, is to start a current of clean air through the mote-filled air. Figure the motion of the air all round the wire. Looking at its transverse section, we should see the air at the bottom of the wire bending round it right and left in two branch currents, ascending its sides, and turning to fill the partial vacuum create above the wire. Now as each new supply of air, filled with its motes, come; in contact with the hot wire, the clean air, as jus stated, is first started through the inert motes. They are dragged after it, but there is a fringe of cleansed air in advance of the motes. The two purified fringes of the two branch currents unite above the wire, and, keeping the motes that once belonged to them right and left, they form by their union the dark band observed in the experiment. This process is ince-sant. Always, the moment the mote filled air touche: the wire, the distribution is effected, a permanent dark band being thus produced. Could the air and the particles under the wire pass through its mass, we should have a vertical currest of particles, but no dark band. For here, though the uotes would be left behind at starting, they would hotly follow the ascending current, and thus aboli-h the darkness."

Prof. Frankland (Proc. Roy. Sor, vol. xxv, p. 542), on the other hand, considers that what is proved by the above described observations is that " a very large proportion of the suspended particles in the London atmosphere consists of water and other volatile liquid or solid matter."

Last summer (I 88r) I repeated and extended Tyndall's beautiful experiment, not feeling satisfied with the explanation of the dark plane given by the discoverer. Too much stress, it appeared to me, is placed upon the relative lightening of the air by heat. The original den-ity is probably not more than about $\mathrm{r} /$ roooth part of that of the particles, and it is difficult to see how a slight further lightening could produce so much effect. In other respects, too, the explanation was not clear to me. At the same time I was not prepared to accept Prot. Frankland's view that the foreign matter is volatilised.

The atmosphere of smoke was confined within a box (of about the size of a cigar-box), three of the vertical sides of which were composed of plates of glass. A beam of sunlight reflected into the darkened room from a heliostat was rendered convergent by a large lens of somewhat long focus, and made to pass in its concentrated condition through the box. The third glass side allowed the observer to see what was going on inside. It could be removed when desired so a; to facilitate the introduction of smoke. The advantages of the box are twofold. With its aid much thicker smoke may be used than would be convenient in an open room, and it is more easy to avoid

I Paper read at the Royal Society, December 21, 1882, by Lord Rayleigh, F.R.S., Professor of Experimental Physics in the University of Cambridge. draughts which interfere greatly with the regularity of the phenomena to be observed. Smouldering brown paper was generally used to produce the smoke, but other :ubstances, such as sulphur and phosphorus, have been tried. The experiment was not commenced until the smoke was completely formed and had come nearly to rest. In some respects the most striking results were obtained from a copper blade about $\frac{1}{4}$-inch broad, formed by hammering flat one end of a stout copper rod. The plane of the blade was horizontal, and its length was in the line of sight. The unhammered end of the rod projected from the box, and could be warmed with a spirit-lamp. The dark plane was well developed. At a moderale distance above the blade it is narrow, sometimes so narrow as almost to render necessary a magnifying glass; but below, where it attaches itself to the blade, it widen; out to the full width, as shown in the figure

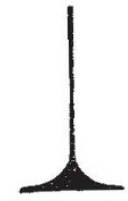

Whether the heated body be a thin blade or a cylindrical rod, the fluid rasse; round the obstacle accordin $r$ to the electrical law of flow, the stream-lines in the rear of the obstacle being of the same form as in front of it. This peculiarity of behaviour is due to the origin of the motion being at the obstacle itself, especially at its hinder surface. If a stream be formed by other means, and impinge upon the same obstacle without a difference of temperature, the motion is of a different character altogether, and eddies are formed in the shadow.

The difference of temperature necesiary to initiate these motions with this dark plane accompaniment is in-ignificant. On July 20 , I88I, a glass rod, a'rout $\frac{1}{4}$-inch in diameter, was em. ployed. It was heated in a spirit-lamp, and then inserted in the smoke-box. The dark plane gradually became thinner as the rod cooled, but could be followed with a magnifier for a long time. While it was still quite distinct the experiment "as stopped, and on opening the box the glass rod was found to be scarcely warmer than the fingers. It was almost imfossible to believe that the smoky matter had been evaporated.

In order to test the matter more closely, smoke was slowly forced through a glass tube heated near the end pretty strongly by a spirit-lamp, and then allowed to emerge into the concentrated sunshine. No distinct attenuation of the smoke could be detected even under this treatment.

It is not necessary to dwell further upon these consideration;, as the question may be regarded as seltled by a decisive experi. ment tried a few days later. The glass rod before u ed was cooled in a mixture of salt and ice, aad after wiping was placed in the box. In a short time a dark plane extending downwards from the rod, clearly developed itself and persisted for a long while. Thi re:ult not merely shows that the dark plane is not due to evap ration, but also excludes any explanation depending upon an ausmentation in the difference of densitie; of fluid and foreign matter.

The experiment was varied by using a U-tube through which cooled water could be made to flow. When the water was not very cold the appearances were much the same as with the solid rod; but when by means of salt and ice the tube was cooled still further, a curious complication presented itself. Along the borders of the dark plane the smoke appeared considerably brivhter than elsewhere. Sometimes when the flow was not very regular it lcoked at first as if the dark plane had been replaced by a bright one, but on closer examination the dark plane could be detected inside. There seems no doubt but that the effect is caused by condensation of moisture upon the smoke due to the chilling which the damp air undergoes in passing close to the cold obstacle. Where the fog forms more light is scattered, hence the increased brightı.ess. That the fog should not form within the smoke-free plane itself is what we might expect from the interesting observations of Aitken.

With respect to the cause of the formation of the dark plane, the most natural view would seem to be that the relatively dense particles are thrown outwards by centrifugal force as the mixture flows in curved lines round the obstacle. Even when the fluid is at rest a gradual suhsidence must take place under the action of gravity; but this effect could at first only manifest itself at the top where the upper boundary of the gas prevents the 